\title{
Research and Application of Cost Control in College Students' Innovation and Entrepreneurship Team
}

\author{
Na Yang \\ School of Automotive Engineering \\ Harbin Institute of Technology \\ Weihai, China
}

\author{
Yiqun Liu* \\ School of Automotive Engineering \\ Harbin Institute of Technology \\ Weihai, China \\ *Corresponding Author \\ Xiaojing Zhou \\ Logistics Security Department \\ Harbin Institute of Technology \\ Weihai, China
}

\author{
Jie Zhou \\ School of Economics and Management \\ Harbin Institute of Technology \\ Weihai, China
}

\author{
Congsheng Li \\ Network Center Office \\ Harbin Institute of Technology \\ Weihai, China
}

\begin{abstract}
With the continuous development of the national attention to innovation and entrepreneurship, colleges have thought more of it in their dimension, so that many of them have carried out kinds of activities and measures, and invest funds to support innovation and entrepreneurship activities. This paper describes the importance and recommendations of cost control theory in the application of college students' innovative entrepreneurial team. For those excellent teams in the process of development, capital is a necessary link, but more resource is used in education and research in universities. This kind of application can't be ignored in the future. The application of cost control has been used in HRT, a student racing team, and gain great success. If the team has awareness of applying the cost control to their own development, on the one hand, the team can use the limited funds to achieve the expected goals, on the other hand, team can learn from the process of cost control and gain the knowledge, to further improve themselves to grow faster and better.
\end{abstract}

Keywords - cost control; college students team; innovation and entrepreneurship; practice research

\section{INTRODUCTION}

In September 2014, Premier Li Keqiang issued a call of "public entrepreneurship, innovation" at the Summer Davos forum, and proposed to give a new wave of "public business" in china. Since then, he has mentioned and explained this keyword frequently in a variety of occasions. Then, E\&I become a popular hot spot, and all over the country, most

Project (BKQN201608) Supported by Harbin Institute of Technology at Weihai, and Project (HIT (WH) 201601) Supported by the Scientific Research Foundation of Harbin Institute of Technology at Weihai. organizations carry out the work to support this viewpoint Subsequently, the State Council also issued "on the development of public space to promote public innovation and entrepreneurship guidance" to encourage public innovation. As national education cradle and talent gathering, universities are also actively involved. Many college students' innovative entrepreneurial teams constantly appear to practicing the guidelines of E\&I [1].

But innovation is not just a simple slogan, to be pragmatic, it takes a lot of work for innovation and entrepreneurship to be succeed. With the continuous development of the national attention to innovation and entrepreneurship, colleges have thought more of it in their dimension, so that many of them have carried out kinds of activities and measures, and invest funds to support innovation and entrepreneurship activities. At present, a large number of outstanding innovative and entrepreneurial teams have emerged in china. For those excellent teams in the process of development, capital is a necessary link, but the resources don't just mean funds, but also includes others related aspects, like venues and equipment. And because more resource is used in education and research, in universities, there are just a little left for teams. Therefore, whether for colleges and universities, or the teams themselves, how to rationally and effectively use the limited funds is a question that must be considered. Cost control is an important means of enterprise cost management. It is a kind of behavior that in the main cost control range, under the pre-established cost management objectives, all kinds of factors and conditions occurring in the activities of the enterprise are in the charge to ensure the realization of the goal of cost management. This kind of application can't be ignored in the future. If the team has awareness of applying the cost control to their own 
development, on the one hand, the team can use the limited funds to achieve the expected goals, on the other hand, team can learn from the process of cost control and gain the knowledge, to further improve themselves to grow faster and better.

\section{Cost Control Problems of College StUdents' INNOVATION AND ENTREPRENEURSHIP TEAM}

The use of cost control in the college students' innovative entrepreneurial team in is still at the starting stage, and there is great difference between the team and the enterprise, and innovation and entrepreneurship student team has a lot of problems still exist in the use of cost control.

In the enterprise, cost control based on value chain theory is popular. Based on the value chain analysis, it takes controlling the cost in the whole progress of production operation and the optimization of the whole value chain as means to create the competitive advantage of enterprises, and urge companies to improve the overall business management, to achieve scientific cost control and industrial value creation from up to down [2].

In the past, the cost control take economy as the focus, emphasizing on reducing expenditure and costs, but the modern cost control management point at sustained economic interests, emphasizing the effectiveness, and it thought if it can generate large economic benefits, it is very advisable to increase the cost [3].

For college students' innovation teams, capital and human resource is more limited compared to social enterprises, therefore, it's not suitable to completely follow the concept of modern enterprises referring to effectiveness. The team should grasp the balance of two kinds of idea and gain experience from them.

\section{A. Cost Control Application Needs Practice Support}

Cost control is an important part of management science, including extensive knowledge and being practical. However, for students, the accumulation of experience is very weak, even though there is the supplement of relative knowledge, it is often mechanically, unable to effectively implement. Otherwise, cost control needs the coordination of accounting personnel, and to a certain extent, their knowledge base determines the quality of cost control. The students freely use the cost control is relatively difficult, which requires team members should make full use of local resources, and actively contact related matters. The project team should be more communication with engineers, factory master, to obtain the actual engineering knowledge and experience, and expand their own ability.

\section{B. It Is Difficult to Control the Cost Steadily}

Cost control is the concept of total control, which is the concept throughout the whole life cycle and the whole process [4]. In the college students' innovation team, one personal contribution period is often for one to two years, some even as less as a few months. in this kind of structure, how to ensure the project cost control in the process of stable continues, is the question that team must consider.

\section{Whole Team Is Not Paying Enough Attention to Cost Control}

The object of cost control is the whole project process, involving all members, and requiring comprehensive experience and knowledge [5]. Therefore, this requires all members have the concept of cost control, considering the design of cost, manufacturing processes, promotion costs and so on, and can be independent thinking. Then, under the management of the manager, the cost control can be effective, so that the whole team profits.

\section{Incentive Measures Are Imperfect}

Cost and project are closely related, but often ignored, especially college students have no social experience and generally cannot recognize the importance of cost control. If you don't pay attention to it, you will naturally slack off. For the team managers, they should not expect team members consciously have cost control consciousness, but through reasonable incentive measures to stimulate them, otherwise the cost control cannot be implemented, the previous efforts will be wasted.

Therefore, the applying of cost control is a great support for the growth of innovative entrepreneurial teams. On the one hand, because the students themselves have no stable sources of funding, on the other hand, in beginning of a program, experience is an extremely resource. This part of the factors make the team in a weaker position. In addition, except for heavy work in the teams, the members are also under miscellaneous and heavy academic pressure. In this position, their expectations for fully and effectively using the funds are strong. If the college students' innovative entrepreneurial teams can learn and apply the knowledge of cost control, and practice it, they may find out that they can operate the program easier.

\section{Cost CONTROL TACTICS OF COLLEGE STUDENTS INNOVATION AND ENTREPRENEURSHIP TEAM}

\section{A. Establish a Simple Cost Control System}

In the enterprise, first of all, according to the industry, management requirements and its production organization system, they determine the object of cost control, and then establish and perfect the system

College Students' innovative entrepreneurial team can imitate this way, according to the team research objects, targets and team attributes to determine the object of cost control, and establish the corresponding system. Because the goal of college student team is single and specific, the cost control system is not as complex and changeable as that of enterprise, and the general object is about fund and time. Moreover, the team of college students has no fixed assets, so it is relatively simple to choose the content and method. Compared with enterprise classification, the cost control contents of college student team can be divided into product cost control, activity cost control, quality cost control and so on. In addition, according to the direction of the team development and organizational goals, there are also capital cost control, environmental cost control, responsibility cost control and others. 
For college students, building a simple system is not an easy task. Team goals should be clear, cost control objects should be targeted, and the most difficult is to link the contents of each part. Because of the different team goals, the control system also has different places. Take team participating in the innovation competition as an example, team target is to make a real item, they can take responsibility cost, time cost as control object, in order to ensure the realization of the goal and achieve project success.

\section{B. Establishment of Phased Cost Control Strategic Planning}

The team members are college students, except for team affairs, other factors like learning, another organization and family are equal, so it will have a strong flow of personnel. How to ensure completing the high cost control in good order has become the key target. The phased and responsibility system construction is a method for cost control planning. The phased cost control planning means that the overall goal is split into stage objectives for management. The cost control process of enterprises is generally divided into three parts: product control before production, product manufacturing process control and product circulation process control [6]. Compared with the actual situation of college students' team, the cost control in college students' innovation and entrepreneurship team can be divided into project planning stage control, project process control and project inspection process control.

The main contents of project planning phase control are project planning cost, procurement cost, project process mode, expected processing cost, etc. Project planning phase control, on the one hand to be planning the next stage of the cost control, has a direct impact on the final cost level; on the other hand, it is the first stage summary and inheritance. The next stage is often relative to the content of the previous stage. The evaluation of the previous stage and experience can help team understand the effect of omission and team advantage, and make guidance for the next phase of the cost target.

\section{Introducing Cost Control Method}

There are many methods of enterprise cost control, including absolute cost control, relative cost control, total cost control, quota method and so on [7]. For college student innovation and entrepreneurship team, because of simple structure and direct goal, they can choose one to two according to their own needs. Due to funding limitations of college students' innovation and entrepreneurship team, the absolute cost control method is appropriate. It emphasizes on controlling the cost in an absolute amount range. For those having a certain economic strength, using the relative cost control method is appropriate. the relative cost control in enterprises is from three factors - the production, cost and income - to consider the cost, but for college students team, these three aspects should be changed into the program, project cost and project income, namely the final product performance, the product cost and product benefits, in which benefits not only refers to the economic benefits, but includes the assistance for members' development, the achievement of this response, and the team's own attribute. Teams in different situations should carefully compare all kinds of cost control methods and choose appropriate indicators according to their own needs. In addition, for those has entered the real team, they are closer to the nature of enterprise, so the considered cost control method is more complex and specific.

\section{Establishment of Cost Control Measures}

How to ensure the effective implementation of cost control is also a very critical aspect. In the cost control and management, it needs to make the assignment from top to bottom, according to the form and function characteristics of team organization, and establish different levels of accountability system and functions of ownership. For the small teams, each person in charge of different content; for a large number of teams, they can mimic the organizational structure of the enterprise to make the division of functions and powers; on the other hand, the team needs a standard and regular transaction processing system. Although some safeguard measures do not directly affect the cost control, it is the cornerstone that whether the cost control can be carried out smoothly.

Among them, the assessment and reward system is a very important part. The team of college students generally has no stable source of economy, and how to improve the enthusiasm of the team requires a good assessment and reward system. In this regard, the team should actively communicate with the school or get sponsors, it will make the team have a foothold on the basis; on the other hand, and honor distribution is also the focus. For team members, in the absence of important factor of income, various factors, like collective interest, sense of honor and achievement is actually quite and important, which requires managers to find out the factors fit the direction of the team as the core, to make the establishment of appropriate reward system.

\section{E. Team Managers Should Play a Key Role in the Establishment of Cost Control Learning Mechanism}

Managers are not always aware of cost control [8]. To continue the process of cost control, it needs a certain mechanism of inheritance. This part should be closely related to the overall system and cultural construction of the team. Good corporate culture construction is closely related to the leadership of managers. In a team, the manager is the image of the team, the whole team leader and strategic orientation. Good managers will guide the subconscious behavior of team members, protect the inheritance of the team imperceptibly, and the cost control mechanism can continue to play a role, to help the team keep stable and lasting development.

\section{F. Expanding Win Value Chain}

Modern production cost management emphasizes the value chain management which expands the value to the whole process of production and management [9]. The application in the innovation and entrepreneurship team, the team should be more cooperated with the school and sponsors, which is an important factor that managers must pay attention to and strive to. Such as the clubs established by HUAWEI, Baidu and other large enterprises, they are popular among the students due to some practice and even push free, and internal staff training from enterprises. Thus, if the team can establish win-win value chain combined with stakeholders, they will get more support 
from school or business, and can get some feedback from the social knowledge and technology enterprises, and they can grow more stably.

\section{Practice Research on Cost CONTROL OF COLlEGE STUDENTS' TEAM}

\section{A. Introduction of HIT Racing Team}

Harbin Institute of Technology Racing Team, referred to as HRT, is built by the Harbin Institute of Technology (Weihai) Automotive Engineering Institute as an international team to participate in the global FSAE competition. It is also one of the earliest students' racing team.

All members should complete the design, manufacture and testing of four racing cars throughout a year through unity and collaboration among the systems. Since the founding of the team, the team continued to get high scores in the domestic FSAE event, having lots of proprietary technology. And in 2016, they got double crown honor. HRT are also active to compete with the world class team, from now on, it has been go aboard to Japan, German, American to join international events. Honors and awards of HRT are shown in "Fig. 1". All of which is closely related to the team's good management.

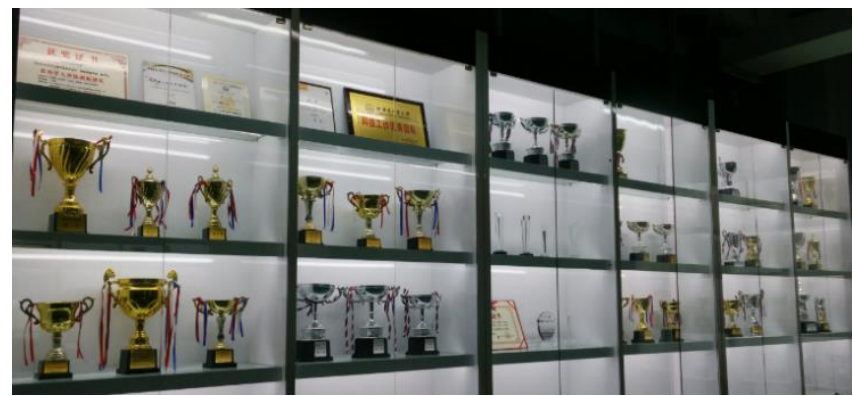

Fig. 1. Honors and awards of HRT.

Among all the management means of HRT, cost control has gotten gradual attention in recent years. Through cost control, the team manages the vehicle manufacturing, testing and other aspects. In such a high cost and competitive industry, the HRT team has supported three powerful university racing teams through cost control, and is also supporting fourth highly sophisticated unmanned vehicle teams. The effective application of cost control to college students' innovation and entrepreneurship team is evident.

\section{B. Manufacturing and Testing of a Season through Cost Control Planning}

The organizational structure of HRT is similar to enterprise management in the division system, respectively designing different types of cars for the four teams, and each team includes power, chassis, body and electrical, business systems. According to the specific design and content, each system has own different classification.

In the process of operation, each team have the meeting at the beginning of a season, to discuss the cost goal of the season through the understanding of the previous vehicle cost, performance and other aspects about the improvements. To do so, on the one hand is to remind members to have a planning goal of the whole season, on the other hand is to provide a regulatory basis for the later audit process and direction. At the same time, each system has more specific and detailed planning on the whole basis. The team also emphasizes the concept of cost control in the design process, players not only consider the performance improvement, while also considering the machining process, which not only makes the design more reliable, but also reduces time and money waste in the later stage of mistaking machining process like unstandardized design, unable of manufacturing condition.

\section{Planning Time Arrangement through Cost Control}

Time is also an important factor for the team. The team members are from different professions, with different programs, the pursuit of self is also inconsistent, so they take the cost of each individual in the course of time into account to arrange the schedule, to avoid the conflict between design and learning situation test. In the cost control system, the weekly regular meeting of the fleet will undergo process check to supervise the completion of the schedule and remind the control for cost. Through this management, the whole team has made great progress in the past two years, and each system can accomplish or even surpass the initial set goals, and also receive good results.

\section{Training Engineering Quality of Members through Cost Control}

Under the background of social economic environment, in the case of accelerating rising production cost and increasing social competition, more and more enterprises are aware of the importance of saving resources and controlling costs [10]. The car industry belongs to the traditional manufacturing industry, it is facing the oppression of cost. We let the members understand and learn the concept of cost control, apply management method of cost control, which very fit the needs of modern enterprises and let the team know that cost control is an indispensable link in engineering practice, so that they can more directly and earlier contact details in the process of production and processing, and can effectively cultivate students engineering quality, support them on the road of excellent engineers.

\section{CONCLUSION}

The methods of cost control have been used in HRT successfully. It helps the team to have a more resistant structure and cultivate many excellent members. Depending on cost control, HRT grows into one of the best students' racing team in China. This kind of concept will change the loose state of the students' organization at present, and will provide more skilled people to society.

\section{REFERENCES}

[1] Mayongbing and Bozhe, "Research and Exploration on the practice mode of university innovation and Entrepreneurship Education,' Tsinghua Journal of Education, vol. 6, pp. 99-103, 2015.

[2] Zangyong, "Research on enterprise cost control based on value chain theory," Southwestern University of Finance and Economics, 2007. 
[3] Luxiaoyan, "On the current cost control theory in China", 3rd ed., vol. 1. Journal of Hubei Radio \& Televison University, 2006, pp. 105-107.

[4] Zhangyin, "Discussion on total cost control," Work \& Study Abroad, vol. 18, pp. 99, 2011.

[5] Huanglihua and Hexiaoming, "Discussion on perfecting the internal control system of enterprises in China," Enterprise Economy, vol. 11, pp. 23-25, 2007.

[6] Lipeisheng, "Research on internal cost control system of target oriented enterprises," Tianjin University, 2008.

[7] Zhangshounan, "A review of the development process of cost control theory," Commercial Times, vol. 26, pp. 82-83, 2012.

[8] Guyapin, "Discussion on production cost control of industrial enterprises," Business Economy, vol. 24, pp. 42-43, 2013.

[9] Songyang, "Research and application of the whole process control of product cost," Market Modernization, vol. 19, pp. 234-235, 2014.

[10] Shicongcong and Jiali, "New challenge of enterprise cost environment in China," Oriental Enterprise Culture, vol. 18, pp. 56, 2010. 